\title{
Innovación y desarrollo endógeno en áreas rurales: el caso del Somontano de Barbastro (Huesca, España)
}

\author{
Ma Luz Hernández Navarro \\ Ana Castelló Puig \\ Universidad de Zaragoza. Departamento de Geografía y Ordenación del Territorio \\ mlhernan@unizar.es \\ castello@unizar.es
}

\section{Ma Pilar Alonso Logroño}

Universitat de Lleida. Departament de Geografia i Sociologia

p.alonso@geosoc.udl.es

\section{Ángel Pueyo Campos}

Universidad de Zaragoza. Departamento de Geografía y Ordenación del Territorio apueyo@unizar.es

\section{Resumen}

En este trabajo se analiza la trayectoria reciente de la comarca del Somontano de Barbastro, en la provincia de Huesca. Su potencial de innovación se basa en los recursos endógenos revalorizados y reinterpretados, que tienen en cuenta los aspectos productivos y la dimensión social y cultural. Se han puesto en marcha actividades de desarrollo endógeno que han demostrado capacidad y habilidad para innovar a escala local. Nos ocupamos del Parque Cultural del Río Vero, de la Ruta del Vino y del Proyecto de Marca de Calidad Territorial.

En estas actuaciones innovadoras, en su gestión y en la gestación del actual proyecto de desarrollo territorial ha sido muy importante la existencia de los recursos naturales, patrimoniales, artísticos y agroalimentarios o la formación de los agentes implicados. Pero el factor más importante del proyecto territorial de la comarca del Somontano es la calidad de la gobernanza, que ha hecho posible la competitividad territorial.

Palabras clave: desarrollo territorial; gobernanza; Somontano de Barbastro; Huesca.

Resum. Innovació i desenvolupament endogen en àrees rurals: el cas del Somontano de Barbastre (Osca, Espanya)

En aquest treball s'analitza la trajectòria recent de la comarca del Somontano de Barbastre, a la província d'Osca. El seu potencial d'innovació es basa en els recursos endògens revalorats i reinterpretats, que tenen en compte els aspectes productius i la dimensió social i cultural. S'han posat en marxa activitats de desenvolupament endogen que han demostrat capacitat 
i habilitat per innovar a escala local. Ens ocupem del Parc Cultural del Riu Vero, de la Ruta del Vi i del Projecte de Marca de Qualitat Territorial.

En aquestes actuacions innovadores, en la seva gestió i en la gestació de l'actual projecte de desenvolupament territorial ha estat molt important l'existència de recursos naturals, patrimonials, artístics i agroalimentaris o la formació dels agents implicats. Però el factor més important del projecte territorial de la comarca del Somontano és la qualitat de la governança, que ha fet possible la competitivitat territorial.

Paraules clau: desenvolupament territorial; governança; Somontano de Barbastre; Osca.

Résumé. Innovation et développement endogène des zones rurales: le cas de Somontano de Barbastro (Huesca, Espagne)

Cet article analyse l'histoire récente du pays du Somontano de Barbastro dans la province de Huesca. Leur potentiel d'innovation est basée sur les ressources endogènes réévaluées et réinterprétées, en tenant compte de sa dimension productive, sociale et culturelle. Ils ont commencé des activités de développement endogène, qui ont démontré la capacité et l'aptitude à innover au niveau local. Nous nous occupons dans cet article du Parc Culturel du Río Vero, de la Route des Vins et de la marque de qualité territoriale proposée.

Ces activités innovantes dans la gestion et création du projet de développement territorial actuel ont été très importantes par l'existence de ressources naturelles, du patrimoine, de l'art, ou de l'agroalimentaire. Mais le projet le plus important du territoire du pays de Somontano est la qualité de la gouvernance, qui a rendu possible la compétitivité territoriale.

Mots clé: développement territoriale; gouvernance; Somontano de Barbastro; Huesca.

Abstract. Innovation and endogenous development in rural areas: the case of Somontano de Barbastro (Huesca, Spain)

This work analyzes the recent history of Somontano region, Huesca province. Its innovation potential is based on revalued and reinterpreted endogenous resources, which take into account productive aspects and the social and cultural dimension. Endogenous development activities have been started up, showing both skill and ability to innovate on a local environment. We will focus on Río Vero cultural park, the wine road, and the Territorial Quality Brand Project.

It has been of great importance the availability of natural, patrimonial, artistic and agro alimentary resources or the growth of involved elements in the management of these innovative actions and the development of the current territorial development project. But the key factor of the territorial project of Somontano region is the quality of its governance, that has made possible territorial competitiveness.

Keywords: territorial development; governance; Somontano de Barbastro; Huesca.

\section{Sumario}

\section{Introducción Conclusiones}

La política territorial europea, el desarrollo y la innovación en áreas rurales

Agradecimientos

Estudio de caso:

Referencias bibliográficas

el Somontano de Barbastro 


\section{Introducción}

La globalización no significa la desaparición del ámbito local. Al contrario, con ella el concepto de desarrollo rural-local ha ido evolucionando hasta llegar al enfoque de desarrollo territorial. En los últimos años se han ido consolidando nuevas pautas de comportamiento en la escala local, preferentemente compatible con la global (Savy y Veltz, 1995).

Durante décadas, el medio rural se ha definido por contraposición a lo urbano. No obstante, en los últimos años las diferencias entre lo rural y lo urbano se han ido diluyendo progresivamente y la tendencia es hacia la complementariedad mutua, siendo razonable que se vayan intensificando las interrelaciones económicas y sociales. Compartimos el planteamiento del Foro IESA (VV. AA., 2009a) cuando afirma que las políticas públicas deben impulsar estrategias de cooperación entre el medio rural y el medio urbano, y favorecer las sinergias necesarias entre ellos, con el objetivo de aprovechar los recursos tanto endógenos como exógenos para situarlos en la senda que lleve al desarrollo sostenible de los territorios. En un momento de crisis y cambios necesarios como el actual, es indispensable que el futuro de los territorios europeos se base en la interacción de lo urbano y lo rural con el fin de lograr la cohesión social y económica y la sostenibilidad ambiental de esos territorios, como ya señalaban los consejos europeos de Lisboa (2000) y de Gotemburgo (2001) o la Agenda Territorial de la Unión Europea 2020 (2011).

Desde este enfoque, uno de los principios de la política europea es conseguir un desarrollo territorial policéntrico y una nueva relación entre campo y ciudad para superar la dualidad o incluso el enfrentamiento. Este planteamiento se deriva del cambio de visión y de la asimilación del desarrollo rural como endógeno, integrado y participativo, ascendente, multisectorial y descentralizado, donde la cooperación interna y externa y la organización en red son imprescindibles, y en el que los distintos sectores de la actividad se integran en una lógica de innovación. Son distintas formas de actuar que constituyen, en definitiva, un nuevo paradigma científico y político, aunque su utilización como referente es reciente en el tiempo (Savy y Veltz, 1995; Radr, 2000; Noguera y Esparcia, 2008; Noguera, Pitarch y Esparcia, 2010; Castelló y Hernández, 2008). Las diversas actuaciones que se llevan a cabo favorecen la consideración de una nueva ruralidad desde la perspectiva del paradigma territorial acorde con el modelo de desarrollo endógeno, en cuyo análisis se vuelven muy útiles algunos instrumentos conceptuales elaborados por la economía regional para el estudio de los sistemas productivos locales (SPL) (Fonte, 2006).

Un desarrollo que es posible mediante la innovación y la competitividad, sumando los logros en lo económico-empresarial, en el clima social, en las redes empresariales, en la participación institucional y en el saber hacer de los agentes locales. En definitiva, todo lo que configura un SPL donde la cooperación entre los actores locales es imprescindible (Méndez, 2002). Pero para lograr el éxito de estos procesos no solo son necesarias las innovaciones empresariales sino que también es necesario que vayan precedidas de una similar innovación 
socioinstitucional, que se construyan con consensos y la formación de redes de cooperación alrededor de estrategias conjuntas (Salom y Albertos, 2009).

En este contexto las zonas rurales pueden adoptar dos posiciones:

- En unos casos son actores indirectos y se consideran meros soportes y contenedores de las actividades y los procesos sociales; en estas ocasiones suelen ser sus características físicas y sociales y su localización las responsables del incremento de su competitividad.

- En otros casos, como sucede actualmente con las zonas más competitivas, y superada la caracterización supeditada exclusivamente al sector primario, adquieren una dimensión de multifuncionalidad; el territorio, en este marco del modelo de desarrollo endógeno, puede ser un actor directo, un agente más, en la consecución de su competitividad.

Como es bien sabido, no todos los territorios rurales comparten las mismas características y circunstancias, ni a escala europea, ni española, ni tampoco aragonesa. En este marco, Izquierdo (2005) señaló que, en el futuro, las sociedades rurales mejor desarrolladas serán aquellas capaces de organizar sus estrategias de desarrollo alrededor de la revalorización del lugar, del conocimiento profundo de lo universal y global y de la pertenencia a una comunidad virtual. Sus recursos, su versatilidad, su capacidad de innovación y la gestión de sus estrategias de desarrollo se convertirán en los factores claves del desarrollo territorial. El éxito de los territorios depende de su capacidad para saber aprovechar y revalorizar los recursos reales y potenciales, materiales e inmateriales (Castelló y Hernández, 2011). Como opina Castells (1996), la ubicación de una ciudad o de un territorio en un lugar o en otro del mundo globalizado no determina su dinamismo económico; el desarrollo se dará más bien por la habilidad y la capacidad de un territorio y de su población para responder y adaptarse a los retos de la competitividad del mercado.

En definitiva, lo local, lo global y lo virtual son las tres concepciones fundamentales para organizar el nuevo mundo rural. Parece indiscutible, por tanto, que en el nuevo paradigma de la economía global basada en el conocimiento se beneficiarán los territorios con mayor capacidad de adaptación a los cambios y que dispongan de las infraestructuras físicas y digitales que les permitan competir en igualdad de condiciones en la escala global.

A partir de estos planteamientos, en este trabajo tratamos algunas cuestiones del proyecto de desarrollo territorial de la comarca del Somontano de Barbastro (Huesca, España), cuya trayectoria encaja con los planteamientos que acabamos de exponer. Su potencial de innovación se basa en sus recursos endógenos revalorizados y reinterpretados, teniendo en cuenta los aspectos productivos y la dimensión social y cultural. Desde hace dos décadas, se ha favorecido la presencia de redes, tanto las cortas de proximidad, de cooperación y concertación para conseguir la cohesión social interna, como otras a mayor distancia para conseguir la competitividad externa, que haga compatible lo local y lo global. El objetivo es encuadrar los procesos de desarrollo territorial generales en este 
territorio. Antes de exponer las actuaciones que se están llevando a cabo en el Somontano de Barbastro, vamos a ver algunos aspectos concretos de la política territorial europea, particularmente en lo que concierne a la innovación.

\section{La política territorial europea, el desarrollo y la innovación en áreas rurales}

La política actual de desarrollo rural de la UE ha ido creciendo a partir de un historial de programación que reconoce el papel clave y los beneficios que ofrecen la innovación y la creatividad para los territorios. Han ido surgiendo nuevas oportunidades - innovaciones - para el medio rural que no se planteaban hace unas décadas y que reflejan los cambios sociales que se viven y que hablan de nuevas respuestas en este momento de crisis y cambios necesarios.

Con la perspectiva que ofrece el tiempo transcurrido y la diversidad de acciones realizadas en territorios muy diversos, se puede afirmar que la innovación es un proceso muy complejo. Como ya decía en 1997 el Grupo de Trabajo sobre Innovación del Observatorio Europeo Leader, esta puede seguir una diversidad de estrategias y pueden existir soluciones múltiples a un mismo problema. La innovación se define, entonces, como una iniciativa de los agentes locales que aporta una respuesta nueva a los problemas específicos de cada territorio con el objetivo de explorar nuevas vías de desarrollo. Cada territorio debe ser flexible, capaz de responder a todo tipo de cambios y lo suficientemente versátil para adaptarse a sus propias necesidades y oportunidades (López Pardo, 2010).

Para Vázquez (1999), la innovación obedece a un proceso interactivo en el que los actores que integran el sistema local de innovación participan en la planificación, de tal forma que la innovación surge de un complejo sistema de mecanismos de retroalimentación y sinergias entre todos: las empresas, los agentes locales, las instituciones públicas, las entidades privadas etc. La innovación y la competitividad territorial se alcanzan sumando a los logros en lo económico-empresarial los relacionados con el clima social, las redes empresariales, la participación institucional y el saber hacer de los agentes locales, es decir, las señas de identidad; en definitiva, las relaciones entre personas, territorios y productos. En función de cómo se construyan las redes entre ellos será posible o no avanzar en el proceso. $\mathrm{Y}$ en este camino unos territorios lo consiguen y otros no, unos ganan y otros pierden (Moncayo, 2002).

Incidiendo en estas cuestiones, en el marco de la política regional de la UE la innovación se manifiesta en tres aspectos: la diversificación de las economías locales; la intensificación de las interacciones entre el contexto local y el global, y la profundización de las relaciones entre los agentes locales, enfocadas a alcanzar nuevas sinergias internas o locales (Grupo de Trabajo sobre Innovación, 1997; VV. AA., 2009b).

En este sentido, la innovación suele ser el resultado de unos intensos contactos y una cooperación con interesados de otros lugares, del trabajo en grupo y en red, y, por supuesto, de la cooperación entre territorios, lo que permite, además, apoyar una mejor gobernanza del territorio. Multifuncionalidad, innovación y gobernanza se convierten en los ejes centrales de la cohesión territorial. 
Lógicas de innovación de los territorios rurales en función de lls tipos de contexto

Tipo de contexto

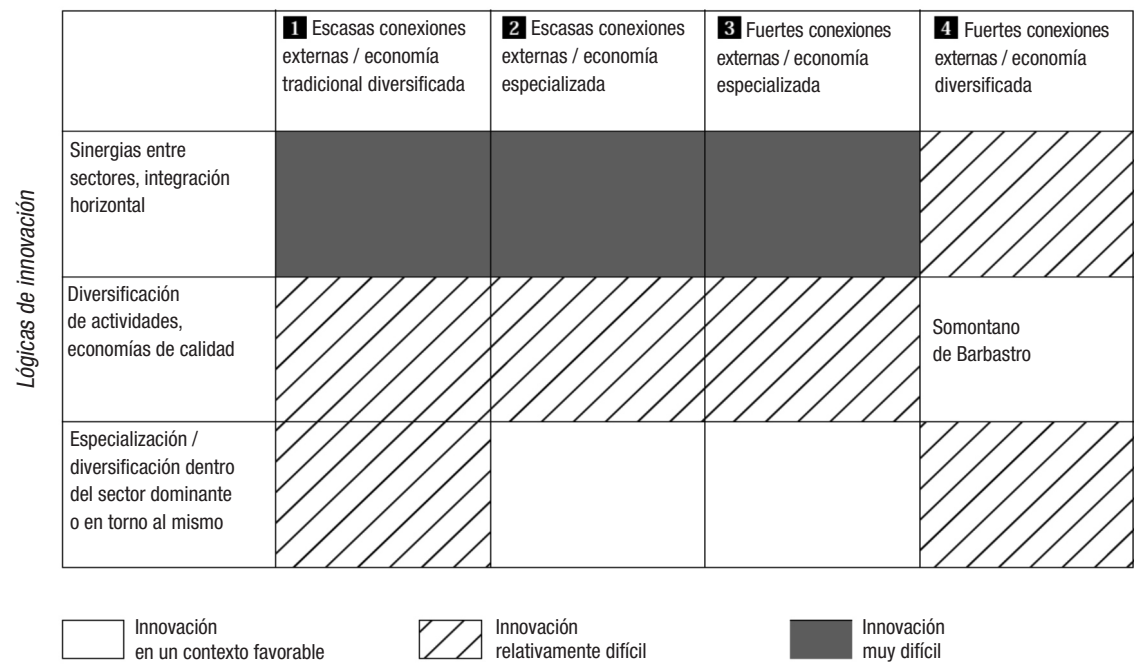

Figura 1. Posición del Somontano de Barbastro (Huesca) en la lógica de innovación de los territorios rurales en función de los tipos de contexto.

Fuente: Modificado de Grupo de Trabajo sobre Innovación (1997).

El Grupo de Trabajo sobre Innovación (1997) establece diferentes tipos de contexto, según el grado de diversificación de la economía local y el grado de apertura del territorio al mundo exterior, que favorecen o dificultan la innovación territorial. La posición favorable del Somontano de Barbastro, que podemos ver en este gráfico, nos ha llevado a tomarlo como estudio de caso para este trabajo.

Según cuál sea el contexto de los distintos territorios, las acciones innovadoras van siendo cada vez más complejas. Y así, los territorios en una posición más favorable, como consideramos que es la del Somontano de Barbastro, buscan la innovación mediante acciones que supongan la interconexión de los agentes locales y que afecten a varios sectores de actividad que cooperan en iniciativas comunes, a partir de las cuales se desarrollan conexiones tanto entre sus redes internas como con el mundo exterior. Analizamos, a continuación, el caso del Somontano de Barbastro.

\section{Estudio de caso: el Somontano de Barbastro}

La comarca del Somontano de Barbastro pertenece a la provincia de Huesca y se sitúa en el piedemonte pirenaico. Está constituida por 58 núcleos de población distribuidos en 29 municipios, que en su gran mayoría (un $76 \%$ ) están considerados como zona desfavorecida, y un $7 \%$ dentro de la zona de 
montaña. Cuenta con 24.428 habitantes (IAEST, 2012). Su evolución sociodemográfica la ha convertido en una comarca con baja densidad de población ( $21 \mathrm{hab} / \mathrm{km}^{2}$ ), envejecida (el $23 \%$ de los habitantes tienen más de 65 años) y con una desequilibrada distribución de la población, las actividades económicas y las infraestructuras, equipamientos y servicios (el $70 \%$ se concentra en la ciudad de Barbastro, que como capital comarcal aglutina la práctica totalidad de los equipamientos, servicios e infraestructuras especializados).

Con una actividad económica algo más diversificada y una renta per cápita algo superior a la media aragonesa, su estructura productiva se ha caracterizado, como en otras comarcas aragonesas, por la pérdida de población activa en el sector agrario, que representa un $10,3 \%$ del valor añadido bruto (VAB), si bien en los últimos años el dinamismo del sector vitícola y el empuje al olivo contribuyen a mantener lo agrario en la comarca, tanto en población ocupada como en VAB. De hecho, el sector agrario tiene mayor peso en esta comarca que la media aragonesa, donde representa el 4,8 \% del VAB. El sector industrial (17 \% de la población activa, $23 \%$ del VAB), que había sido significativo en los subsectores eléctrico y químico, ha perdido importancia en la última década. No obstante, la agroindustria se perfila como elemento dinamizador del sector $y$, dentro de ella, la industria vitivinícola, que revaloriza el nombre de la comarca a través de la denominación de origen (DO) Somontano.

Como en muchas otras áreas rurales, el sector servicios es el que más ha crecido recientemente. Supone el 61,2 \% de los activos y casi el $50 \%$ del VAB (IAEST, 2012). Este sector ha crecido desde las últimas décadas del siglo XX debido tanto a la reconversión del comercio tradicional como a la aparición de nuevas actividades ligadas al turismo rural, a la revalorización del patrimonio y a la diversificación económica en general, favorecida por las estrategias de desarrollo rural de enfoque territorial implantadas en el Somontano de Barbastro desde 1995 .

Desde esa fecha, el Somontano ha buscado la potenciación de los recursos endógenos, lo que ha conducido a que el medio natural se haya patrimonializado ${ }^{1}$ y convertido en un bien económico a través de la consideración de varias figuras de protección, entre las que destacan cinco lugares catalogados como LIC (lugares de importancia comunitaria) y una ZEPA (zona de especial protección para las aves), con más de 20.000 hectáreas cada uno, un parque natural, el de mayor extensión de Aragón, y un parque cultural, uno de los cinco existentes en esta comunidad. La gran riqueza del patrimonio natural y cultural, tanto material como inmaterial, constituye un capital territorial de gran valor, que ha decantado el empleo y la creación del VAB al sector servicios como prioritario por ocupación de población activa y por aporte de riqueza.

Por tanto, el desarrollo de esta comarca se ha basado en la puesta en valor de un rico patrimonio natural y cultural, y en el mantenimiento y revaloriza-

1. En los municipios del norte de la comarca, la superficie clasificada como espacio natural protegido oscila en una proporción entre el $43,3 \%$ y el $69,4 \%$ de la superficie municipal. 
ción de las actividades agrarias, sobre todo del cultivo de la vid y la reciente potenciación del olivo, con excelentes potencialidades todavía poco utilizadas, que provocan sinergias entre distintos sectores de la actividad económica, como la agroindustria y el turismo y otros servicios vinculados a ellas. A esta revalorización del medio como recurso económico se añade el saber hacer tradicional, en una zona en la que el intercambio de productos ha sido constante con todos sus vecinos, incluida Francia, con quien colabora en proyectos europeos desde hace más de una década. Entre estos proyectos de cooperación internacional destaca su participación en Territoria Universitates, Desarrollo sin FronterasDéveloppement sans Frontières, cofinanciado por la Iniciativa Comunitaria Interreg III A Francia-España. ${ }^{2}$

No obstante, con ser esto importante, consideramos que los factores de desarrollo inmateriales en este territorio han sido varios:

- Por una parte, la identidad territorial, la revalorización del sentimiento de pertenencia al territorio de la población. Este ha fomentado el asociacionismo en la comarca y ha permitido que trabajen de forma coordinada desde mediados de los años noventa la administración local (tanto el Ayuntamiento de Barbastro como otros ayuntamientos de la comarca), la propia comarca del Somontano y el Centro de Desarrollo Integral del Somontano (Ceder Somontano) y la iniciativa privada. Destaquemos que el Ceder está constituido por 17 entidades que representan al $90 \%$ de la población y más de 300 empresas.

- Por otra parte, lo que consideramos más relevante ha sido saber aprovechar la oportunidad que brinda el actual paradigma de desarrollo con la valoración de los recursos endógenos y considerando el territorio como agente de desarrollo, lo que supone una fortaleza y una oportunidad por su estratégica ubicación en el contexto aragonés.

En esta comarca el éxito de las actuaciones, que se están llevando a cabo desde mediados de la década de los noventa, depende en gran medida de la redistribución de las actividades en el medio rural y de la participación activa de todos los núcleos de población en la toma de decisiones a través de sus representantes políticos. Estos han gestionado muy bien la generación de capital social a partir de la puesta en práctica de una gobernanza territorial acorde con las propuestas de desarrollo territorial que se han aplicado y han obtenido resultados muy satisfactorios (Quasar Consultores, 2008).

Como es lógico en muchos territorios, la innovación es fruto de lo que el Grupo de Trabajo sobre Innovación del Observatorio Europeo Leader denomina un descubridor o un nuevo líder local (ya sea un individuo, un grupo o una institución), que en el caso de Barbastro comienza en la década de los ochenta con la denominación de origen vitivinícola Somontano de Barbastro,

2. Se puede consultar dicho proyecto en http://www.aragonrural.org/territoria/index. php?option=com_content\&view=frontpage\&lang=es 
que da los primeros pasos para situar esta comarca en el mundo, y que siembra el germen de lo que más tarde será un proyecto de enfoque territorial.

Poco a poco se fueron encontrando socios que se sumaron a la idea de proyecto territorial. En este sentido, el Ceder Somontano y la metodología Leader han desempeñado un papel fundamental desde su nacimiento en 1995. A ellos se han unido, más recientemente, la administración local, sobre todo la comarca del Somontano y el Ayuntamiento de Barbastro, como hemos dicho. Desde entonces, además de la Agenda 21 y otros programas, han gestionado Leader II, Leader +, Leader 2007-2013 (responsabilidad del Ceder) y otros, entre los que destacan Adapt o Terra y, más recientemente, Pon Aragón en tu mesa o Red Natura 2000. Esta consolidación del enfoque territorial de los programas y actuaciones de desarrollo del Somontano ha sido posible gracias a la labor de animación del Grupo de Acción Local, su papel aglutinador de las diferentes y plurales sensibilidades del capital social y el trabajo en red con otros actores locales del territorio.

Así mismo, la construcción de esta seña de identidad ha sido posible por la implantación de la comarcalización en Aragón, la descentralización administrativa y la capacidad de decisión que ha asumido la comarca.

Así pues, consideramos que se trata de un territorio innovador porque se han puesto en marcha actividades de desarrollo endógeno que han demostrado la capacidad y la habilidad para innovar en la escala local. Para este proyecto territorial, se han reinterpretado y revalorizado los recursos endógenos considerando los aspectos productivos y la dimensión social y cultural, y como en otras zonas rurales, las experiencias de desarrollo se han realizado con la puesta en práctica de una nueva forma de trabajar. Todo ello ha sido posible gracias al cambio de modelo de desarrollo que se ha producido en la comarca al modificar la toma de decisiones y de relaciones, que se realiza en la escala local próxima al ciudadano (Castelló y Hernández, 2008). Con este modelo de desarrollo, son los habitantes los que participan en la toma de decisiones y en la configuración de su propio territorio, obviados antes por el modelo económico centralizado y descendente. Actualmente, el protagonista de este modelo es la persona, que es el motor de cambio y cuya inteligencia y conocimiento del territorio dan forma a las sociedades (Vachón, 2001).

Como ya hemos dicho, el Somontano de Barbastro lleva trabajando en estos proyectos y estrategias de desarrollo rural de enfoque territorial desde 1995. A lo largo de este tiempo se han desarrollado casi seiscientas actuaciones, la mayor parte distribuidas por todo el territorio y muchas de las cuales han dado lugar a la creación de empresas y, por lo tanto, de empleo.

En el periodo 1996-2001 se gestionó Leader II, además de otros programas, como Adapt, para la mejora de la competitividad de las empresas locales y sus asociaciones, o Terra, para la puesta en valor del patrimonio cultural, especialmente el Parque Cultural del Río Vero. Esta es una de las actuaciones de enfoque territorial que han mejorado la gobernanza del territorio y que han permitido que muchos proyectos de pequeño tamaño hayan sido posibles al amparo del parque cultural como elemento aglutinante. 
Tabla 1. Actuaciones y empleo creado en la comarca del Somontano de Barbastro entre 1994 y 2013

\begin{tabular}{lcccc}
\hline & Actuaciones & Empleo creado & $\begin{array}{c}\text { Empleo } \\
\text { consolidado }\end{array}$ & Empleo total \\
\hline Leader II & 324 & 261 & 52 & 261 \\
LEADER + & 128 & 158 & 55 & 210 \\
LEADER 2007-2013* & 126 & 43 & $\mathbf{1 0 7}$ & $\mathbf{5 6 9}$ \\
\hline Total & 578 & 462 & \\
\hline
\end{tabular}

* hasta mayo de 2013

Fuente: Ceder Somontano. Elaboración propia.

Los parques culturales ${ }^{3}$ nacieron en Aragón en 1997 como figura exclusiva de esta comunidad autónoma, tras una década de desarrollo de actividades relacionadas con la protección, la investigación y la conservación de un rico patrimonio. Esta figura regularizó, normalizó y legitimó lo que de hecho ya se estaba gestionando en materia de conservación y protección del patrimonio, y que se había demostrado eficaz para el desarrollo sostenible en el ámbito rural aragonés. La conjunción naturaleza y cultura ya había iniciado su andadura y estaba desempeñando un papel muy relevante como recurso patrimonial en el desarrollo territorial.

En el caso que nos ocupa, desde entonces, en la Mancomunidad del Somontano se había iniciado una apuesta planificada y con voluntad de servir como eje y elemento estructurante de la economía local. Esta mancomunidad la componen nueve municipios: Bárcabo, Alquézar, Colungo, Adahuesca, Santa María de Dulcis, Pozán de Vero, Azara, Castillazuelo y Barbastro. Administrativamente, ocho forman parte del sector norte de la comarca del Somontano de Barbastro, y uno, Bárcabo, de la comarca de Sobrarbe. Así mismo, la zona norte del parque está dentro del espacio natural protegido del Parque Natural de la Sierra y Cañones de Guara.

Esto último supuso que los municipios que lo integran priorizasen las inversiones ligadas al parque frente a las de equipamientos e infraestructuras municipales. De este modo, la figura del Parque Cultural del Río Vero ha contribuido a diversificar las actividades económicas de la comarca, a la vez que ha mantenido las tradiciones y señas de identidad de la zona (difícilmente medible con indicadores, pero muy relevante en el enfoque territorial

3. Los parques culturales son espacios singulares de integración de los diversos tipos de patrimonio, tanto el material, el mobiliario y el inmobiliario como el inmaterial, en el marco de las definiciones establecidas por el Consejo de Europa y por la UNESCO. La normativa indica que las actuaciones que se realicen en el mismo tienen que estar orientadas hacia la protección, la restauración del patrimonio, la acción cultural, el desarrollo rural sostenible y el equilibrio territorial y en estrecha coordinación entre las políticas territoriales y sectoriales, especialmente las de patrimonio cultural y natural, fomento de la actividad económica, turismo rural, infraestructuras y equipamientos. Se observa, por tanto, que una vez definidos los elementos considerados como recurso patrimonial, se induce a la puesta en práctica de políticas integradas y con una apuesta clara por la conservación de los bienes patrimoniales, pero renovando su utilidad para generar un nuevo recurso. 


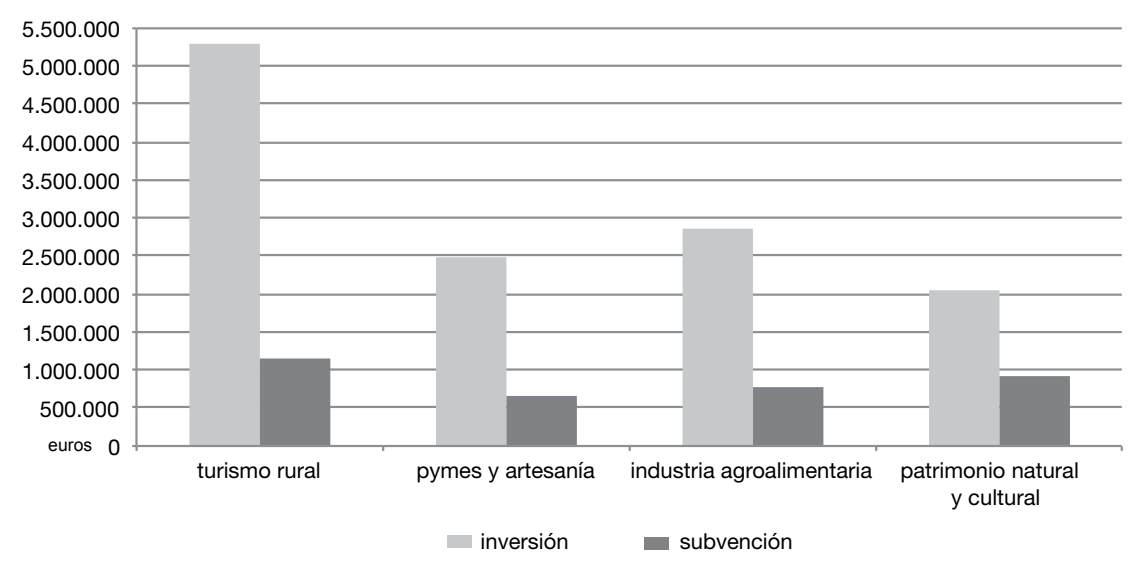

Figura 2. Inversión y subvención por medidas en Leader II.

Fuente: Ceder Somontano. Elaboración propia.

de los proyectos de desarrollo de la comarca). Esta política de desarrollo de la mancomunidad ha supuesto que muchas de las empresas creadas ligadas al turismo (alojamientos, restauración, empresas de aventura) hayan sido favorecidas por la figura del parque cultural (Castelló y Hernández, 2008; Castelló, Hernández y Giné, 2008). Esta relación mutua y la descentralización de competencias para la toma de decisiones en la escala local y comarcal han generado actuaciones innovadoras con incidencia social, económica, ambiental, cultural y global.

Además, se han establecido redes externas con otros territorios con la idea de crear una ruta cultural del sur de Europa: el proyecto Terra Incógnita, con la participación de quince territorios europeos, se concibe con el objeto de la gestión sostenible del patrimonio cultural para la ordenación del territorio de cinco áreas del Mediterráneo.

La gestión conjunta, descentralizada y participativa de estas actuaciones e iniciativas permitió que, entre 1996 y 2001, la inversión realizada en actuaciones de desarrollo rural en el Somontano de Barbastro se basara en el potencial agroalimentario y el patrimonio natural y cultural.

De hecho, el turismo rural fue la medida que registró más inversión y más actuaciones, así como la modernización de las industrias agroalimentarias de la vid y, en menor medida, del olivo. Se mejoraron las pequeñas bodegas, tanto de origen familiar como cooperativo, se implantaron sistemas de calidad y se introdujeron nuevas tecnologías para sentar las bases de lo que actualmente es una de las acciones paradigmáticas del Somontano, como es la Ruta del Vino, junto con el Parque Cultural del Río Vero y la Marca de Calidad Territorial.

En definitiva, se creó una oferta de productos de calidad que, además, han supuesto un activo importante en la oferta turística del Somontano. 


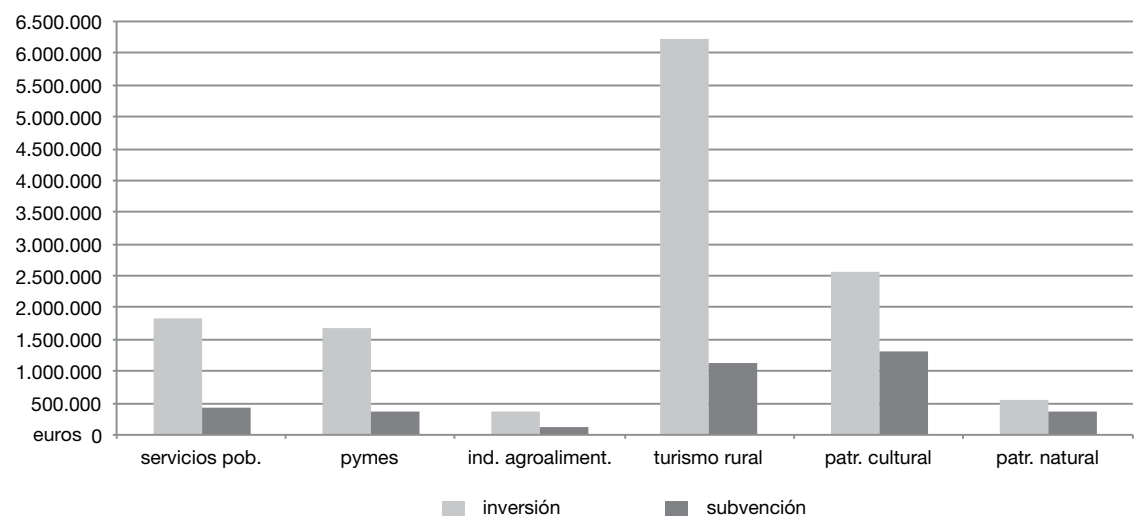

Figura 3. Inversión y subvención por medidas en Leader +.

Fuente: Ceder Somontano. Elaboración propia.

De 2001 a 2008 se gestionó Leader,$+^{4}$ que continuó con la estrategia iniciada en la etapa anterior. De nuevo, la actuación conjunta en el territorio, liderada por el Ceder Somontano, impulsó la conservación, rehabilitación, interpretación y difusión del patrimonio cultural y natural. Se consolidó el parque cultural como referente del turismo y como base de la creación de nuevos productos de turismo cultural. Todo ello impulsó la articulación y la promoción de unos recursos turísticos de calidad diferenciada, procurando la distribución territorial de las actuaciones y de las subvenciones. De hecho, en este periodo, el $86 \%$ de las actuaciones tuvieron su sede fuera de la capital de la comarca y se concentraron en el turismo rural.

Desde 2008 se gestiona en la comarca el programa Leader 2007-2013, incluido como eje 4 en el Programa de Desarrollo Rural de Aragón. Hasta finales de 2012 se han aceptado 131, con lo que se prevé realizar una inversión de casi 9 millones de euros (2,3 millones de euros en Leader II y 14,8 millones en Leader + ). De nuevo, el fomento de actividades turísticas y la promoción de la industria agroalimentaria es lo que concentra la mayor parte de las inversiones, que se favorecen de las sinergias logradas desde mediados de los noventa entre los distintos sectores y que han tenido en consideración su diversificación en el territorio.

En la etapa actual, las circunstancias económicas han ralentizado el desarrollo de nuevos proyectos, sobre todo por las dificultades de acceso al crédito. De este modo, los esfuerzos se están centrando en consolidar los resultados obtenidos en los últimos veinte años para poder mantener las empresas y los puestos de trabajo que se han ido creando.

4. Aunque el periodo de programación de Leader + es 2000-2006, el programa se desarrollo entre 2001 y 2008. 


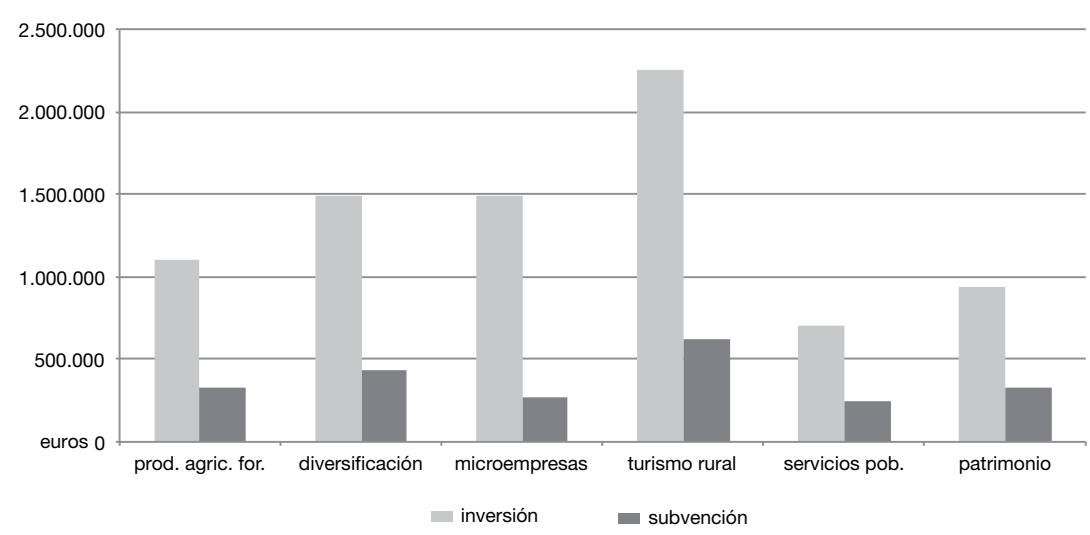

Figura 4. Inversión y subvención por medidas en Leader 2007-2013.

Fuente: Ceder Somontano. Elaboración propia.

En este esfuerzo están desempeñando un papel muy importante tres iniciativas que consideramos esenciales para un desarrollo rural en esta comarca con un enfoque territorial: el Parque Cultural del Río Vero, ya enunciado, la Ruta del Vino del Somontano y la Marca de Calidad Territorial.

La Ruta del Vino del Somontano es un proyecto territorial construido desde la propia identidad, que tiene como eje temático el vino y su cultura. Con ello, se quiere facilitar la comercialización conjunta del territorio y garantizar la competitividad y calidad del producto final. Promovido por la Asociación Española de Ciudades del Vino (Ácevin), bajo la tutela de los ministerios de Industria, Energía y Turismo, y de Agricultura, Alimentación y Medio Ambiente, su principal objetivo es potenciar el sector como motor de otras actividades (turismo, promoción económica, empleo, protección del medio natural, etc.).

Si bien la denominación de origen es de los años ochenta, la producción de vino es una de las actividades económicas que otorgan una seña de identidad a esta comarca al vincular el producto con el territorio. De hecho, es muy significativa esta relación de las marcas de comercialización del vino con el territorio: el $61 \%$ de ellas tienen nombres que tienen que ver con lo local, lo endógeno, bien sean nombres geográficos del medio natural (identificaciones con el nombre de los parajes donde se cultivan las viñas, la toponimia utilizada en las labores de cultivo), nombres o expresiones propias de la zona, usos, costumbres y tradiciones. Por todo ello, es muy oportuno que el topónimo Somontano haya sido el escogido para generar confianza e identificación por parte de la población local y externa para transmitir una información relacionada con la calidad, el buen hacer y la reputación de todos los productos de la zona, reduciendo de manera drástica el nivel de asimetría informativa que habitualmente preside la relación producción-consumo, y que supone una fortaleza para competir en los mercados para buena parte de las empresas y servicios de la zona (Arfini, 2006). 
Este proyecto, de forma similar a como lo ha hecho el Parque Cultural, ha conseguido involucrar a la población, las empresas, las instituciones y asociaciones contando con la utilización de recursos endógenos y exógenos, todos al unísono para conseguir un desarrollo económico, social y medioambiental.

La Ruta del Vino del Somontano está gestionada por la Asociación para la Promoción Turística del Somontano, entidad sin ánimo de lucro creada en el año 2005 por el Ayuntamiento de Barbastro, la comarca del Somontano y el Consejo Regulador de la Denominación de Origen Somontano (Asociación para la Promoción Turística del Somontano, 2011). El proyecto definitivo se aprobó en 2006 y pasó a formar parte de las Rutas del Vino de España al entrar en la oferta internacional a través de los canales establecidos por la Secretaría General de Turismo. La complejidad de esta actuación deriva de la necesidad de aunar esfuerzos y establecer redes de cooperación interempresariales e interinstitucionales, lo que en el Somontano de Barbastro ha sido más fácil por las acciones de gobernanza que ya se habían ido poniendo en práctica en la comarca desde la década de los ochenta (Castelló y Hernández, 2011).

El predominio del vino se deja notar en la pertenencia al proyecto de un número mayoritario de bodegas, incluso algunas de ellas procedentes de las comarcas colindantes, que se han adherido utilizando sus lazos de pertenencia a la denominación de origen Somontano.

Desde sus inicios, para su adhesión a la Ruta, ha sido necesario verificar los niveles de calidad, lo que no ha sido obstáculo para duplicar su número de asociados, que en seis años ha pasado de 34 en 2006 a 87 en 2012.

Como en el resto de actuaciones de esta comarca, y teniendo en consideración los objetivos de equidistribución territorial, los proyectos de emprendedores no se localizan únicamente en Barbastro, sino en 26 núcleos de población que representan más del $45 \%$ de las entidades, además de en otros que pertenecen a comarcas colindantes por las que también se extiende la DO.

Además del mecenazgo y patrocinio de actividades lúdicas y culturales, también está la participación en el proyecto denominado «Hacia un modelo de competitividad, sostenibilidad y gobernanza en el medio rural», liderado por el Ministerio de Agricultura, Alimentación y Medio Ambiente, de manera que la Ruta del Vino del Somontano se ha convertido en Territorio Enoturístico Socialmente Responsable, concebido como una herramienta piloto de primer orden para hacer de la comarca del Somontano un territorio que sabe actuar conjugando los aspectos económicos, sociales, ambientales y culturales, e involucrando a todos los agentes sociales, entidades públicas y privadas, asociaciones y centros de enseñanza e investigación.

Actualmente en la comarca se está trabajando para la consecución de la Marca de Calidad Territorial, con la intención de que sea aceptada en el club de calidad europeo, liderado por la Marca de Calidad Europea, Calidad Rural. Se trata de una marca adicional, compartida con todos los territorios rurales de la Unión Europea, que aporta el valor añadido de la territorialidad y proporciona masa crítica y capacidad para ser reconocida y valorada por el consumidor. Con esta marca se pretende entrar y triunfar en el mercado global salvando las dificultades de una marca local aislada. 
Es una estrategia de desarrollo rural puesta en marcha por la Unión Europea durante el periodo de ejecución de la Iniciativa Comunitaria Leader, en la que la innovación se basa en introducir nuevas maneras de trabajar y nuevas iniciativas en los procesos de producción, en los servicios y en la manera de concebir el territorio en sí mismo como un producto objeto de innovación global. Pero es, ante todo, un sistema de calidad que ofrece garantías a las empresas que llevan la marca y a los consumidores finales sobre los productos del medio rural (AMCTE, 2012)..$^{5}$

Esta comarca cuenta con el caldo de cultivo necesario para que se haya gestado este proyecto de enfoque totalmente territorial, ya que posee unos recursos endógenos favorables, un emplazamiento estratégico, una economía diversificada, una excelente producción y comercialización de los vinos, un enorme potencialidad turística, unos variados paisajes naturales y culturales, una fuerte percepción de la identidad territorial por la población local, y un modelo de trabajo coordinado y en equipo de instituciones, empresas, administraciones públicas y Ceder.

El fundamento conceptual de la estrategia responde a la demanda creciente de los consumidores de territorios rurales que, además de las funciones de producción de las materias primas, cumplan otras como bienes públicos y como conservación del medio ambiente, de las tradiciones culturales, de la identidad, del equilibrio demográfico y de la cohesión social y territorial (AMCTE, 2012).

Actualmente, la comarca del Somontano de Barbastro está en vías de certificación de su Marca Territorial Local Somontano-Guara, una vez concluida la fase preparatoria, iniciada en el año 2009.6 El nombre hace referencia al propio del territorio y a la sierra más emblemática, Guara, catalogada como parque natural y ejemplo significativo de lo que supone revalorizar un recurso natural y cultural que había sido abandonado, olvidado y relegado.

El proceso preparatorio para la creación de la Marca Territorial Local ha supuesto el desarrollo de distintas fases, como: dinamización del territorio, definición de la identidad territorial y creación de la identidad de la marca, elaboración de los instrumentos y exposición pública, y evaluación de la Marca de Calidad Territorial Local respecto a la MCTE — que es el proceso en el que está en estos momentos.

5. En España, los Grupos de Acción Local (GAL) ligados a los centros de desarrollo son los que han tomado la iniciativa para conseguir este distintivo de calidad para sus zonas de competencia, adhiriéndose al proyecto de cooperación Adquisición de la Marca de Calidad Territorial financiado por el Ministerio de Medio Ambiente y Medio Rural y Marino. Actualmente existen en España veintiuna marcas territoriales que cumplen los indicadores de calidad establecidos por el Reglamento Europeo y, en consecuencia, pueden usar el distintivo Calidad Rural de la Unión Europea. También está implantado en Grecia, Italia y Francia.

6. Están en vías de certificación dieciocho territorios de toda España. En Aragón, además de la Marca Somontano-Guara, están en este trámite las Tierras del Jiloca y Gallocanta y las comarcas Comunidad de Calatayud, Aranda, Bajo Martín y Andorra-Sierra de Arcos, cuya adhesión es inminente. Puesto que el proceso está abierto, es muy arriesgado citar el número exacto de territorios adheridos (http://www.calidadterritorial.es/en-vias-certificacion/index. htm) (28.06.2012). 


\section{Los efectos territoriales: competitividad, innovación y gobernanza en el Somontano}

Estos proyectos han permitido dar respuestas innovadoras y competitivas a algunas debilidades tradicionales de la comarca al conseguir involucrar a las empresas locales preexistentes y favorecer la aparición de otras nuevas, la deslocalización y el desarrollo de un trabajo en red que se ve favorecido por el desarrollo de los servicios digitales y las tecnologías de la información y de la comunicación (Vanier, 2008).

La aplicación del método de trabajo ascendente y participativo ha dado como resultado el que las actuaciones implantadas y las empresas y empleos creados sean difíciles de atribuir a uno u otro programa (Leader, Terra, Parque Cultural, Ruta del Vino u otros), puesto que el objetivo final es la interacción entre todos los programas y agentes de desarrollo. Por ello, y porque los resultados de las acciones conjuntas los recoge el Ceder Somontano en su conjunto, nos remitiremos a ellos. No obstante, nos parece importante señalar que los logros obtenidos desde mediados la década de los noventa se deben contabilizar no solo cuantitativamente, en lo que se refiere a la creación y deslocalización de empresas y empleos, sino también desde una perspectiva cualitativa, en cuanto a la generación de un excelente capital social que ha sido clave para gestionar la gobernanza territorial.

Estas experiencias de desarrollo han contribuido a la diversificación económica de la comarca, uno de los objetivos de las estrategias actuales de desarrollo rural, hasta el punto que el sector agrario ocupa el tercer lugar en lo que a población activa se refiere, después de los servicios y de la industria. De hecho, la población activa agraria era del $52 \%$ en el sector primario en 1991 y del 10,9\% en 2011, mientras que en servicios era del $24 \%$ en 1991 y del $61,2 \%$ en 2011 ; la población activa industrial se mantenía estable ( $15 \%$ en 1991 y $17,8 \%$ en 2011) y también la construcción (9 \% en 1991 y $10 \%$ en 2011).

La gestión de estos programas ha dado lugar a la creación de 93 empresas en los dieciocho años de funcionamiento del Centro de Desarrollo y a más de 550 puestos de empleo, creados o consolidados, como vemos en las tablas 2 y 3 .

El turismo rural ha sido una de las actividades que más ha crecido, especialmente en las pequeñas localidades, lo que ayuda a la diversificación económica y a la corrección de los desequilibrios internos entre Barbastro y el resto de la comarca. De hecho, el $90 \%$ de los alojamientos turísticos y el $50 \%$ de los restaurantes están repartidos entre doce municipios. Actualmente, más de doscientas empresas turísticas representan casi el $15 \%$ de las empresas locales y ofertan cerca de tres mil plazas de diferente categoría y modalidad (3,5\% de Aragón).

En este sentido, Leader ha contribuido decisivamente a este desarrollo fomentando establecimientos de calidad media-alta, apoyando servicios de ocio complementarios (deportes de aventura, centros hípicos, etc.), incentivando el turismo cultural y el ornitológico o reforzando los lazos con la industria agro- 
Tabla 2. Actuaciones y empleo creado en el marco de Leader en el Somontano de Barbastro (1995-2013)

\begin{tabular}{lcccc}
\hline & Actuaciones & Empleo creado & $\begin{array}{c}\text { Empleo } \\
\text { consolidado }\end{array}$ & Empleo total \\
\hline Leader II & 324 & 261 & & 261 \\
Leader + & 128 & 158 & 52 & 210 \\
Leader 2007-2013* & 126 & 43 & 55 & 98 \\
\hline Total & 578 & 462 & 107 & 569 \\
\hline
\end{tabular}

* hasta mayo de 2013

Fuente: Ceder Somontano. Elaboración propia.

Tabla 3. Empresas creadas en el marco de Leader en el Somontano de Barbastro (1995-2013)

\begin{tabular}{lcccccc}
\hline & $\begin{array}{c}\text { Valorización } \\
\text { de productos } \\
\text { Empresas creadas }\end{array}$ & Turismo & $\begin{array}{c}\text { Pymes } \\
\text { y servicios }\end{array}$ & $\begin{array}{c}\text { Servicios } \\
\text { a la } \\
\text { población }\end{array}$ & $\begin{array}{c}\text { Plazas de } \\
\text { alojamiento restauración } \\
\text { creadas }\end{array}$ & $\begin{array}{c}\text { Plazas de } \\
\text { creadas }\end{array}$ \\
\hline Leader II & 7 & 16 & 15 & & 360 & 430 \\
Leader + & 4 & 6 & 4 & 20 & 440 & 803 \\
Leader 2007-2013* & 5 & 10 & 5 & 1 & 98 & 201 \\
\hline Total & 16 & 32 & 24 & 21 & 898 & 1434 \\
\hline
\end{tabular}

* hasta mayo de 2013

Fuente: Ceder Somontano. Elaboración propia.

alimentaria. En el periodo actual, el $40 \%$ de las actuaciones (39 actuaciones de las 126 comprometidas con fondos de Leader) corresponden a empresas de turismo y diversificación.

Todos estos programas de desarrollo han favorecido que las empresas agroalimentarias hayan visto mejorar sus resultados económicos trabajando bien ellas solas o en cooperación con otras del entorno o fuera del mismo.

La Ruta del Vino constituye otro de los pilares sobre los que se potencia la diversificación económica: selección de bodegas, empresas y servicios turísticos (alojamientos, restaurantes, bares, comercios especializados, agencias de viajes, compañías de transporte) y una rica oferta de ocio (museos, deportes de aventura, establecimientos hidroterapéuticos, centros de interpretación), de tal modo que la implicación, colaboración y cooperación de las empresas del territorio es significativa (Castelló y Hernández, 2011). La figura 5 muestra los establecimientos adheridos a la Ruta del Vino. Como vemos, bodegas, restaurantes y alojamientos son, lógicamente, los más numerosos. Porcentualmente suponen un $50 \%$, un $25 \%$ y casi un $10 \%$ respectivamente. Los alojamientos representan un menor porcentaje, ya que únicamente se adhieren los de mayor calidad. A ellos hay que añadir incluso un establecimiento hidroterapéutico y un comercio virtual. 


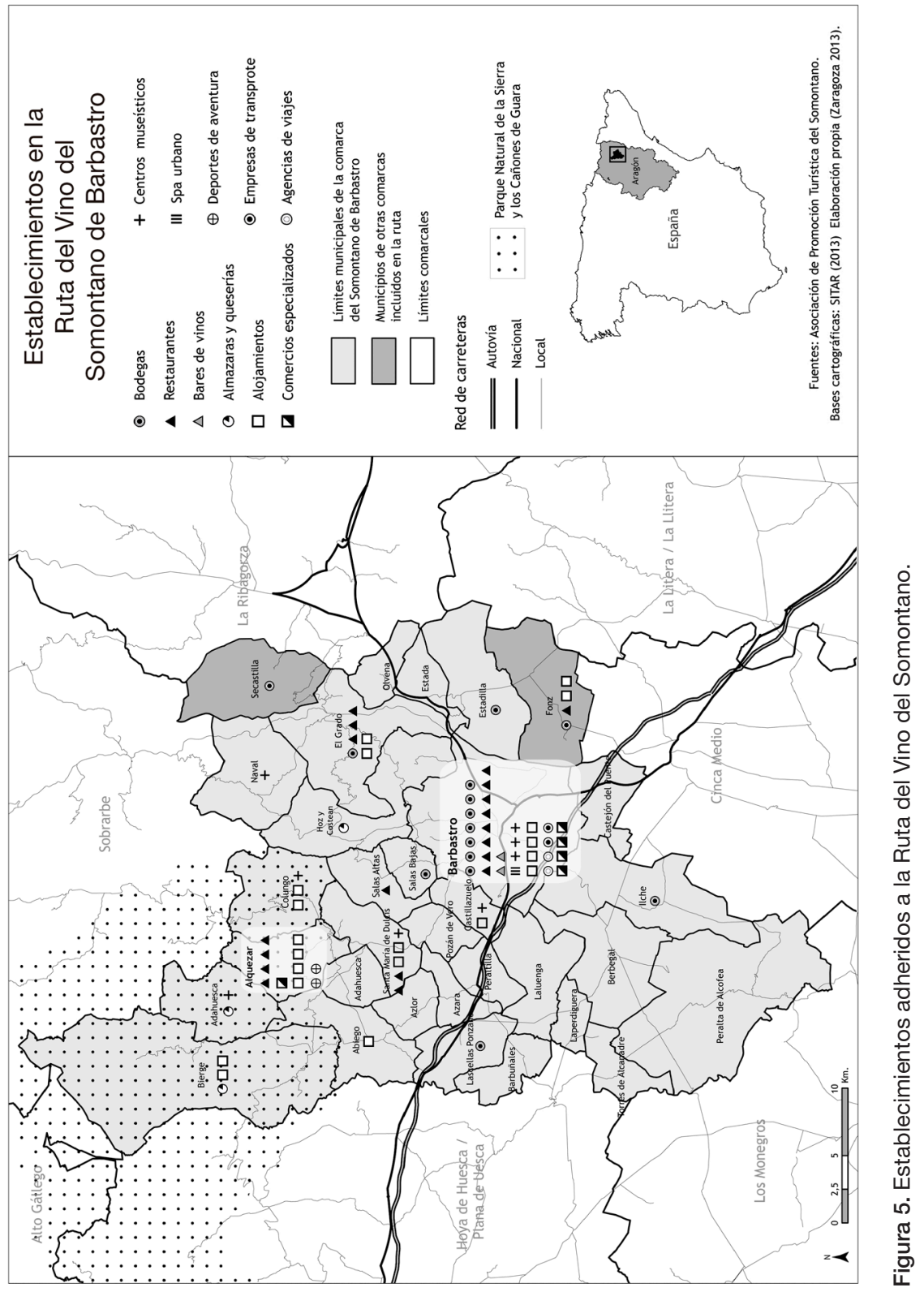


Se ha favorecido el cambio de funcionalidad de antiguos edificios, algunos abandonados, para instalar hasta ocho museos y centros de interpretación, tres de ellos en Barbastro y el resto repartidos por la comarca, como el Centro del Arte Rupestre de Colungo, el de Alfarería de Naval, el de Aceite en Buera o el Centro de Leyendas y Tradiciones de Adahuesca. Se han creado empresas de deporte de aventura que, salvo una que está en Barbastro, las demás hasta un total de doce están en la zona rural, y lo mismo podemos decir de una industria artesana agroalimentaria que aprovecha el saber hacer tradicional para la transformación de productos autóctonos.

Asimismo, se han instalado empresas de diferentes actividades relacionadas con la rehabilitación, la restauración, la cantería y otros oficios.

Todas estas actuaciones han contribuido a desestacionalizar la oferta turística, que se ha adaptado a las potencialidades de cada periodo estacional: catas y talleres de vino y aceite, visitas a las bodegas y a los centros de interpretación, juegos enogastronómicos, vinoterapia y rutas de senderismo por el entorno natural y cultural, entre otras, apoyadas por las TIC en la promoción de la Ruta del Vino con fondos de Leader.

Es importante destacar el papel de los jóvenes como promotores de actuaciones. Alrededor del $44 \%$ de las actuaciones productivas están promovidas por personas menores de cuarenta años, lo que cualitativamente está contribuyendo a frenar la despoblación de los pequeños municipios.

Siendo estos resultados muy relevantes, ha supuesto también innovación en la esfera de lo inmaterial el cambio de actitud de los agentes sociales, de las autoridades locales y de los particulares en relación con la consideración de los recursos propios, ya que se ha acrecentado su autoestima y han aprendido a cooperar y compartir, a encontrar nexos de unión no solo entre las empresas y las actividades, sino también con los otros, o a fomentar la cultura del pacto y el consenso en la consecución de los objetivos individuales y colectivos. En esencia, se está respondiendo de una manera acertada y territorializada a reforzar el valor de la gobernanza.

Por todo ello, y a modo de síntesis, la figura 6 muestra la articulación de la innovación y de la deslocalización territorial en la comarca del Somontano de Barbastro a través de la interacción entre sus distintos puntos de apoyo: económico, político, sociocultural y científico-tecnológico.

\section{Conclusiones}

El camino recorrido desde la década de los ochenta y su consolidación con la puesta en marcha de la iniciativa comunitaria Leader II, sus enseñanzas y buenas prácticas, han permitido crear el caldo de cultivo imprescindible para la participación activa de todos los ciudadanos, agentes sociales, instituciones y organizaciones públicas y privadas. Han favorecido el diseño y la gestión de estrategias orientadas a revalorizar y descubrir sus recursos, tangibles e intangibles, fomentando la deslocalización y la promoción del territorio. 


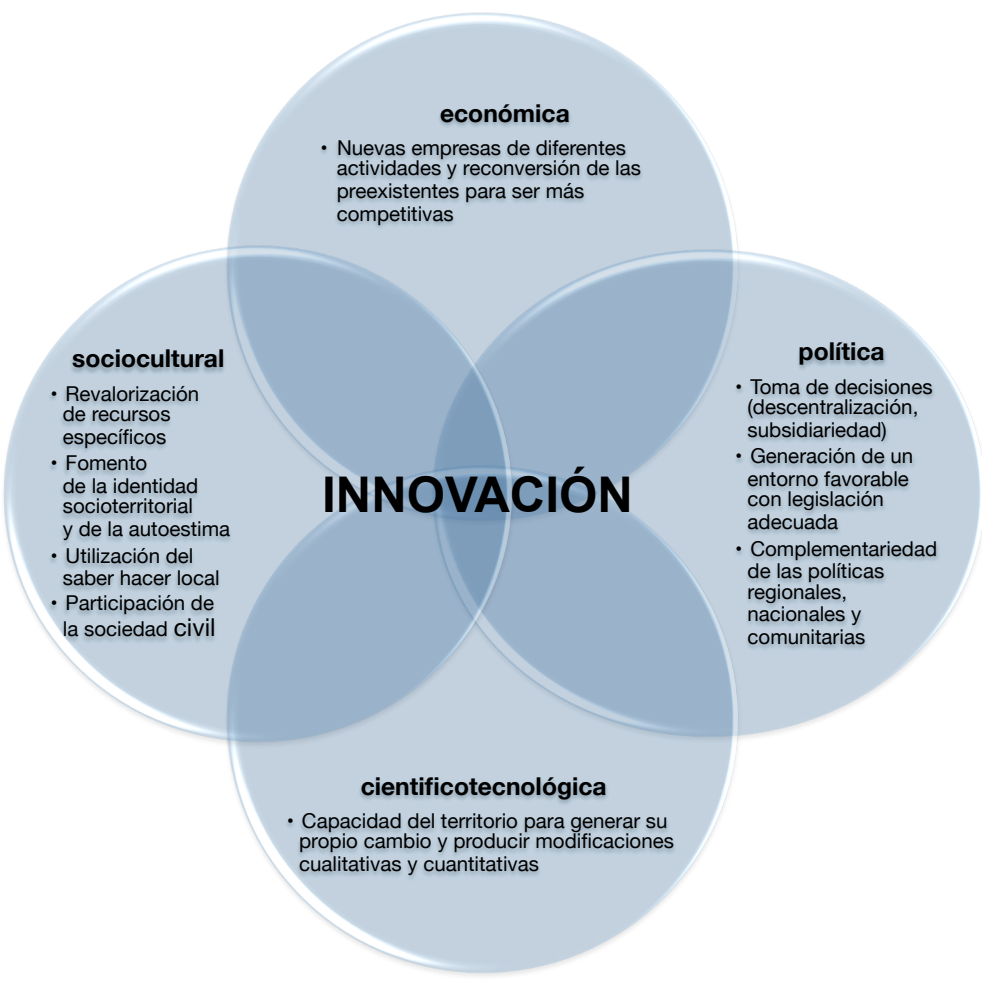

Figura 6. Innovación territorial en el Somontano de Barbastro.

Los diferentes programas y proyectos han actuado como estrategias de diferenciación en este territorio y están fortaleciendo su proyecto de desarrollo territorial convirtiéndolo en innovador y competitivo, ya que:

- ejemplifica un modelo de desarrollo endógeno que tiene en cuenta variables inmateriales antes no consideradas (las instituciones, el capital social, la historia, la cultura, las tradiciones, etc.);

- utiliza metodologías de trabajo ascendentes en el contexto del paradigma de desarrollo territorial, que hace énfasis en las nociones de territorio y territorialidad;

- la metodología Leader ha sido imprescindible porque ha favorecido la participación activa de las instituciones, los agentes sociales, las empresas, la iniciativa privada y los ciudadanos en general;

- al recuperar la dimensión del territorio como agente de desarrollo, propicia la generación de tejidos productivos locales, de pequeñas empresas de especialización flexible y de diferenciación y revalorización del territorio;

- es un sistema productivo inmerso en un entorno singular cuyo desarrollo gira alrededor del patrimonio cultural y natural y la transformación de los 
productos agroalimentarios y ha mejorado su competitividad de forma paralela al cambio de metodología en sus planteamientos de desarrollo.

En estas actuaciones innovadoras, en su gestión y en la gestación del actual proyecto de desarrollo territorial, han sido muy importantes la existencia y valoración de sus recursos naturales, patrimoniales, artísticos, agroalimentarios o de formación de los agentes implicados. Pero la calidad de la gobernanza es uno de los factores de más relevancia para el éxito del proyecto territorial de la comarca del Somontano, ya que ha hecho posible que se consiga la competitividad y la deslocalización territorial.

Ello supone que la innovación no se debe solamente a mejoras materiales o de inversión, sino que también responde a un proceso de carácter fundamentalmente social y ciudadano, manifestado en la presencia de redes cortas de proximidad, de cooperación y concertación para conseguir la cohesión social; y de otras redes espacialmente más largas para conseguir la competitividad externa que haga compatible lo local y lo global, y que se están favoreciendo por el desarrollo por todo el territorio de las tecnologías de la información y de la comunicación.

Este proceso ayuda a conocer las características de los territorios en los que funcionan las redes innovadoras $y$, por tanto, donde el desarrollo parece mostrarse más estable frente a situaciones de crisis como la actual, en un nuevo contexto de cambio económico donde no solo están presentes las grandes aglomeraciones sino también las ciudades medias y los territorios rurales.

\section{Agradecimientos}

Este trabajo se ha beneficiado de la concesión de una ayuda al desarrollo de Redes de Investigadores, Movilidad y Proyectos de Investigación y Desarrollo Tecnológico en el marco de cooperación de la Comunidad de Trabajo de los Pirineos (años 2011-2012), CTPR 02/10, Innovación, Dinámicas Territoriales y Sistemas Locales de Competencias, cofinanciada por el Departamento de Ciencia, Tecnología y Universidad del Gobierno de Aragón.

\section{Referencias bibliográficas}

ARFINI, F. (2006). «Productos típicos y desarrollo rural: entre calidad y políticas de gobernanza». Revista Española de Estudios Agrosociales y Pesqueros (Ministerio de Agricultura, Pesca y Alimentación), 210, 13-30.

Asociación de la Marca de Calidad Territorial Europea (AMCTE) (2012). <http://www.calidadterritorial.es> [Consulta: 25.06.12].

Asociación de Promoción Turística del Somontano (2011). «Ruta del vino. Somontano vive el vino" [en línea]. <www.rutadelvinosomontano.com> [Consulta: 19.01 .11$]$.

Castelló Puig, A. y Hernández Navarro, M. L. (2008). «La gestión local del desarrollo en los albores del siglo XXI en Aragón (España)». En: CORIA, L. G. (2008). La gestión local del desarrollo [en línea]. Biblioteca Virtual de Derecho, Economía y Ciencias Sociales, p. 25-46. <www.eumed.net/libros/2008a/344>.

- (2011). «La ruta del vino del Somontano de Barbastro (Huesca) como proyecto territorial de identidad cultural». Geographicalia, 59-60, 61-72. 
Castelló Puig, A., Hernández Navarro, M. L. y Giné Abad, H. (2008). «El Parque Cultural del Río Vero. De espacio protegido a motor de desarrollo local». En: Molinero, F. (ed.). Los espacios naturales protegidos / Les espaces naturels protégés. III Coloquio Hispano-Francés de Geografía Rural / IIIe Colloque Franco-Espagnol de Géographie Rurale [CD], p. 329-48.

CASTELls, M. (1996). El surgimiento de la sociedad de redes. Blackwell Publishers.

FONTE, M. (coord.) (2006). «Desarrollo rural e identidad cultural: reflexiones teóricas y casos empíricos» [en línea]. <http://www.rimisp.org/getdoc.php?docid=5102>.

GRUPO de Trabajo sobre InNOvación (1997). Innovación y desarrollo rural [en línea]. Bruselas: Observatorio Europeo Leader. Serie Informes del Observatorio, 2. <http://ec.europa.eu/agriculture/rur/leader2/rural-es/biblio/inno/innov.pdf>.

InSTITUTO ARAGONÉS DE ESTADÍSTICA (2012). <http://www.aragon.es/iaest>.

IZQUIERDO, J. (2005). Manual para agentes de desarrollo rural. Madrid: Mundi-Prensa Libros.

LÓPEZ PARDo (2010). «Espacios sociales de innovación». En: II Congreso Nacional de Desarrollo Rural. Zaragoza 8-10 de febrero de 2010 [en línea]. <http://www.coiaanpv. org/recursos/files/web/congresos_y_jornadas/historico_de_congresos/ii_congreso_ desarrollo_rural/documentacion/ponencias/jose_ramon_lopez_pardo.pdf>

MÉNDEZ, R. (2002). "Innovación y desarrollo territorial: algunos debates teóricos recientes». EURE, 84, 63-83.

MONCAYO, E. (2002). Nuevos enfoques teóricos, evolución de las politicas regionales e impacto territorial de la globalización [en línea]. Santiago de Chile: CEPAL-ILPES. Serie Gestión Pública, 27. <http://www.eclac.org/publicaciones/xml/5/11885/sgp27.pdf>.

Noguera Tur, J. y EsParcia PÉREZ, J. (2008). Nuevos factores de desarrollo territorial. Valencia: Universidad de Valencia.

Noguera Tur, J.; Pitarch Garrido, M. D. y Esparcia Pérez, J. (2010). Gestión y promoción del desarrollo local. Valencia: Universidad de Valencia.

QUASAR CONSUlTORES (2008). Evaluación posterior del programa Leader Plus en Aragón 2000-2006 [en línea]. <http://www.aragon.es/estaticos/GobiernoAragon/Departamentos/AgriculturaAlimentacion/Documentos/docs/Areas/Desarrollo_Rural/ Evaluaci\%25C3\%25B3n\%2520Posterior\%2520del\%2520Programa\%2520LE ADER\%2520Plus.pdf>.

RADR (2000). Aragón Leader. El desarrollo rural en Aragón. Zaragoza: Red Aragonesa de Desarrollo Rural.

SAlOM, J. y AlberTos, J. M. (2009). Redes socioinstitucionales, estrategias de innovación $y$ desarrollo territorial en España. Valencia: Universidad de Valencia.

SAVY, M. y Veltz, P. (1995). Économie globale et réinvention du local. La Tour d'Aigües: Éditions de l'Aube - Datar.

Vachon, B. (2001). El desarrollo local. Teoría y práctica. Gijón: Trea.

VANIER, M. (2008). Le pouvoir des territoires. Essai sur l'interterrorialité. París: Economica.

VÁZQUEZ BARQUeRO, A. (1999). Desarrollo, redes e innovación: lecciones sobre desarrollo endógeno. Madrid: Pirámide.

VV. AA. (2009a). "Del desarrollo rural al desarrollo territorial». Foro IESA sobre la Cohesión de los Territorios Rurales [en línea]. <http://www.iesa.csic.es/publicaciones/detallarpublicacion/id/226>.

VV. AA. (2009b). «Innovación rural: aceptar el cambio como una oportunidad». Revista Rural de la UE [en línea]. Núm. 2, 6-9. <http://enrd.ec.europa.eu/app_templates/filedownload.cfm?id=645A64C4-DB42-7EBA-5D54-33F5BD033760>. 